\title{
ER Stress and Its Functional Link to Mitochondria: Role in Cell Survival and Death
}

\author{
Jyoti D. Malhotra ${ }^{1}$ and Randal J. Kaufman ${ }^{1,2}$ \\ ${ }^{1}$ Department of Biological Chemistry, University of Michigan School of Medicine, Ann Arbor, Michigan, 48109 \\ ${ }^{2}$ Department of Internal Medicine, University of Michigan School of Medicine, Ann Arbor, Michigan, 48109 \\ Correspondence: kaufmanr@umich.edu
}

The endoplasmic reticulum (ER) is the primary site for synthesis and folding of secreted and membrane-bound proteins. Proteins are translocated into ER lumen in an unfolded state and require protein chaperones and catalysts of protein folding to assist in proper folding. Properly folded proteins traffic from the ER to the Golgi apparatus; misfolded proteins are targeted to degradation. Unfolded protein response (UPR) is a highly regulated intracellular signaling pathway that prevents accumulation of misfolded proteins in the ER lumen. UPR provides an adaptive mechanism by which cells can augment protein folding and processing capacities of the ER. If protein misfolding is not resolved, the UPR triggers apoptotic cascades. Although the molecular mechanisms underlying ER stress-induced apoptosis are not completely understood, increasing evidence suggests that ER and mitochondria cooperate to signal cell death. Mitochondria and ER form structural and functional networks (mitochondria-associated ER membranes [MAMs]) essential to maintain cellular homeostasis and determine cell fate under various pathophysiological conditions. Regulated $\mathrm{Ca}^{2+}$ transfer from the ER to the mitochondria is important in maintaining control of prosur$\mathrm{vival} /$ prodeath pathways. We discuss the signaling/communication between the ER and mitochondria and focus on the role of the mitochondrial permeability transition pore in these complex processes.

$T$ he ER is an elaborate membranous network present in all eukaryotic cells and responsible for many homeostatic responses that include folding and maturation of newly synthesized secretory and transmembrane proteins (Kleizen and Braakman 2004). In addition, this organelle is also the site of cholesterol and steroid biosynthesis, lipid biosynthesis, assembly of core-asparagine linked oligosaccharides, and membrane and secreted protein biosynthesis. Newly synthesized proteins require proper folding within the ER lumen prior to trafficking to specific destinations in the cell. These cellular processes are initiated when nascent polypeptide chains emerge in ER lumen, where posttranslational modifications such as N-linked glycosylation, and intra- and intermolecular disulfide bond formation facilitate the folding of polypeptides to form specific tertiary and quaternary structures for proper protein function (Molinari 2007). Although the amino acid sequence of the protein determines many

Editors: Richard I. Morimoto, Dennis Selkoe, and Jeff Kelly

Additional Perspectives on Protein Homeostasis available at www.cshperspectives.org

Copyright (C) 2011 Cold Spring Harbor Laboratory Press; all rights reserved; doi: 10.1101/cshperspect.a004424

Cite this article as Cold Spring Harb Perspect Biol 2011;3:a004424 
of these precise processes, numerous proteins, including chaperones and enzymes, aid in proper protein biosynthesis and folding. The key chaperones and folding sensors in the ER include the peptide-binding proteins $\mathrm{BiP}$ and GRP94, the lectins calnexin and calreticulin, and the thiol-disulfide oxidoreductases such as protein disulfide isomerase (PDI) and Erp57. The chaperone machinery collectively cooperates to prevent protein misfolding, aberrant interactions, and aggregation. The quality of protein folding is precisely monitored by an ER quality control system that only allows properly folded proteins to be transported to the Golgi compartment and directs misfolded proteins for ER-associated degradation (ERAD) by the $26 \mathrm{~S}$ proteasome or for degradation through autophagy (Ma and Hendershot 2004; Kincaid and Cooper 2007).

Protein folding in the ER is very sensitive to extracellular stimuli and insults, and intracellular processes that alter $\mathrm{Ca}^{2+}$ homeostasis, redox status, and energy (sugar/glucose) stores. The $\mathrm{ER}$ is the central site for $\mathrm{Ca}^{2+}$ storage and homeostasis within the cell. The ER couples its quality control machinery to the storage and utilization of $\mathrm{Ca}^{2+}$. Alterations in intralumenal $\mathrm{Ca}^{2+}$ can cause protein misfolding because both protein folding reactions and protein chaperone functions require high levels of calcium. Under conditions that compromise ER function, particularly the accumulation of newly synthesized unfolded proteins, the organelle signals activation of an elaborate adaptive process known as the unfolded protein response (UPR) (Ron and Walter 2007). Appropriate adaptation to misfolded protein accumulation in the ER lumen requires regulation at all levels of gene expression including transcription, translation, translocation into the ER lumen, and ERAD. Coordinate regulation of all these processes is required to restore proper protein folding and ER homeostasis (Mori et al. 1993; Patil and Walter 2001; Kaufman 2002; Schroder and Kaufman 2005; Wu and Kaufman 2006). Finally, chronic activation of UPR signaling eventually induces an apoptotic (programmed cell death) response. We will briefly discuss below the various signaling arms of the UPR as relevant to cell survival and adaptation and ER stress as it relates to apoptosis and cellular demise.

\section{UPR SIGNALING: CELL SURVIVAL}

In higher eukaryotic cells, three ER membraneassociated signal transducers sense the presence of misfolded proteins in the ER lumen and initiate adaptive responses (Fig. 1).

These transducers are two protein kinases IRE1 (inositol requiring enzyme 1) (Cox et al. 1993; Yoshida et al. 2001), PERK (PKR-like eukaryotic initiation factor $2 \alpha$ kinase) (Harding et al. 2000a,b), and the transcription factor ATF6 (activating transcription factor 6) (Yoshida 2001; Lee et al. 2002; Yoshida et al. 2003; Yamamoto et al. 2007). Under normal cellular conditions in which the ER is presumably "stress-free," the intralumenal amino-terminal domains of IRE1 and PERK and the carboxyterminal domain of ATF6 are maintained in an inactive state by interaction with the chaperone BiP/GRP78 (Bertolotti et al. 2000; Liu et al. 2003). This model for negative regulation of the UPR by BiP is also supported by the observation that $\mathrm{BiP}$ overexpression prevents activation of the UPR on ER stress (Dorner et al. 1990). Whether BiP is the primary regulator of each UPR sensor is not clearly known, as simple disruption of the interactions between $\mathrm{BiP}$ and the UPR sensors may not result in constitutive activation (Oikawa et al. 2007). Recently, the crystal structure of the yeast Irelp luminal domain (Credle et al. 2005) identified the existence of a deep, long MHC1-type groove in the Ire1p dimer and proposed that unfolded polypeptides directly bind Irelp to mediate its dimerization. However, although analysis of the human IRE1 indicated a similar structure, the MHC1-type groove was not solvent-accessible (Zhou et al. 2006). In addition, the luminal domain was shown to form dimers in the absence of added polypeptide, bringing into question the requirement for peptide binding to promote dimerization. Because these structures represent static conformations, it is possible the altered conformational states may regulate both $\mathrm{BiP}$ and peptide binding. Therefore, it is reasonable to 


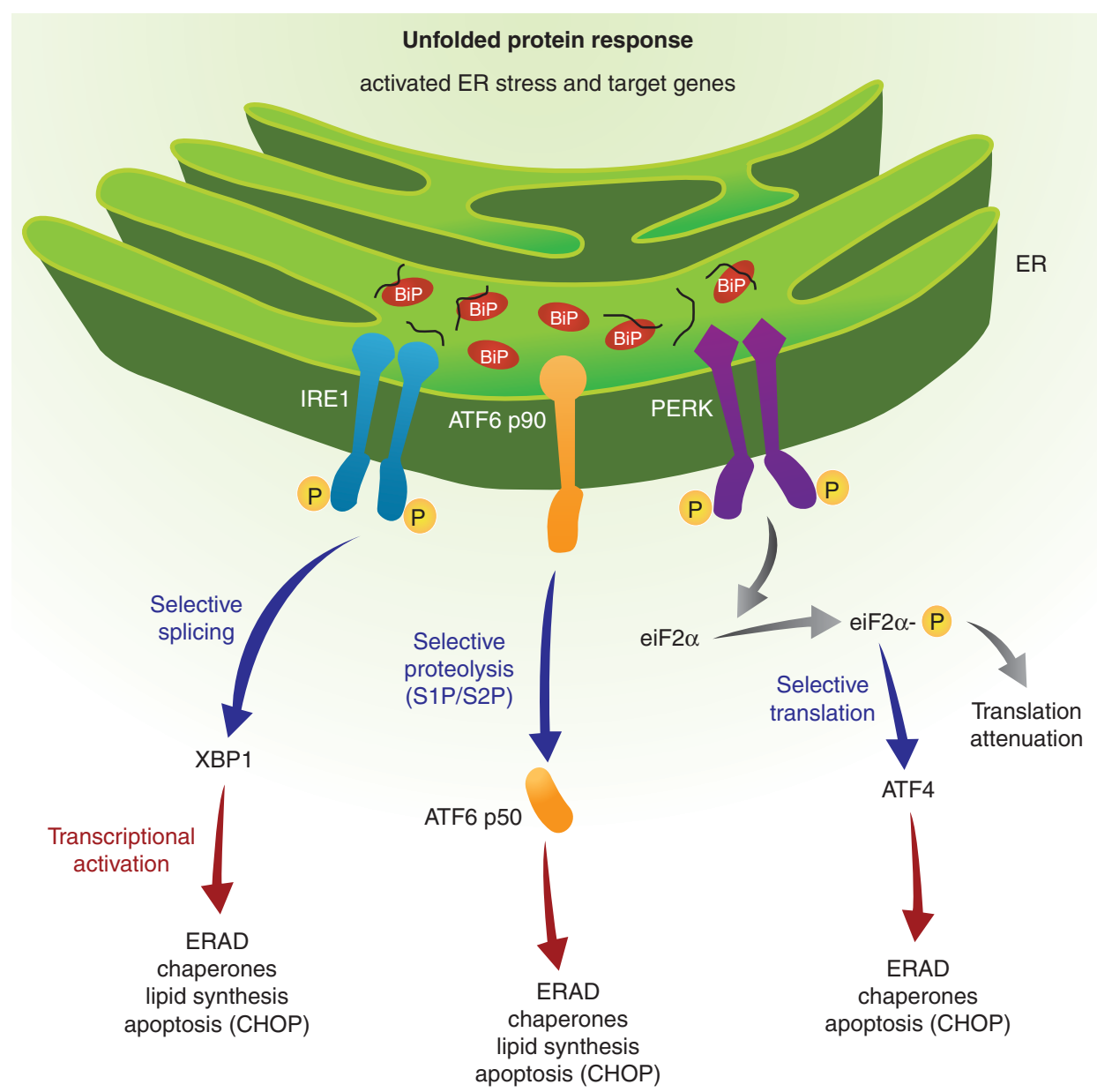

Figure 1. Signaling the unfolded protein response: Three proximal sensors IRE1, PERK, and ATF6 regulate the UPR through their respective signaling cascades. Under nonstressed conditions, BiP binds to the lumenal domains of IRE1 and PERK to prevent their dimerization. On accumulation of unfolded proteins in the ER lumen, IRE1 released from BiP, dimerizes to activate its kinase and RNase activities to initiate XBP1 mRNA splicing, thereby creating a potent transcriptional activator. Primary targets that require IRE1/XBP1 pathway for induction include genes encoding functions in ERAD. Similarly, ATF6 released from BiP transits to the Golgi compartment for cleavage by S1P and S2P proteases to yield a cytosolic fragment that migrates to the nucleus to further activate transcription of UPR-responsive genes. Finally, PERK released from BiP dimerizes, autophosphorylates, and phosphorylates eIF $2 \alpha$ on Ser 51 leading to general attenuation of translational initiation. Paradoxically, eIF $2 \alpha$ phosphorylation induces translation of ATF4 mRNA. The PERK/eIF2 $\alpha /$ ATF4 regulatory axis also induces expression of anti-oxidative stress response genes and expression of genes encoding proteins with proapoptotic functions, such as $\mathrm{CHOP}$.

speculate that BiP binding as well as peptide binding act together to regulate IRE1 dimerization. Future studies in this area should resolve this issue. It is believed that the primary trigger for release of BiP from the sensors is the accumulation of misfolded proteins. This, coupled with other unidentified luminal events, results in oligomerization and activation of the IRE1 and PERK kinases and results in the execution of a complex and fascinating downstream intracellular signaling pathway (Bertolotti et al. 2000; Ron and Walter 2007; Aragon et al. 2009; 
Korennykh et al. 2009; Li et al. 2010). Concomitantly, the third branch of the UPR is activated when ATF6 translocates to the Golgi apparatus where it is cleaved by the serine protease site-1 ( $\mathrm{S} 1 \mathrm{P})$ and the metalloprotease site- 2 protease (S2P) to generate an active transcription factor (Chen et al. 2002). Interestingly, ATF6 activation is also sensitive to the redox status of the cell and recent evidence suggests that only the reduced monomeric form of ATF6 translocates to the Golgi apparatus (Nadanaka et al. 2007). The overall effect of this tripartite UPR signaling is to attenuate the global mRNA translation and simultaneously upregulate the expression of chaperones to improve ER folding capacity and ERAD function. The various branches of the UPR are briefly described below.

In the early 1990s, investigations in the budding yeast $S$. cerevisiae identified the ER stress-regulated kinase and endoribounuclease IRE1 that is conserved from yeast to humans. Two independent groups identified Irelp/ Ernlp as an ER transmembrane protein kinase that acts as a proximal sensor in the yeast UPR that initiates unconventional removal of a 252 base intron within the basic leucine zipper (bZIP) transcription factor Haclp to induce expression of UPR genes (Cox et al. 1993; Mori et al. 1993). Subsequently, several groups showed that X-box binding protein-1 (XBP1) mRNA is the mammalian homolog of yeast Irelp and the substrate for the endoribonuclease activity of mammalian IRE1 (Shen et al. 2001; Yoshida et al. 2001; Calfon et al. 2002; Lee et al. 2002). On activation of the UPR, the endoribonuclease activity of IRE1 cleaves XBP1 mRNA to remove a 26 base intron. This splicing reaction creates a translational frame shift to produce the active (or spliced) form of the transcription factor (XBP1s). Spliced Xbp1 is a transcriptional activator for many of the UPR target genes and, in conjunction with ATF6 $\alpha$, launches a transcriptional program to produce ER protein chaperones and proteins involved in ER biogenesis and phospholipid synthesis with the net effect of expanding the folding capacity of the ER to resolve the proteinfolding defect (Lee et al. 2003). Some of the genes identified that require the IRE1/XBP1 pathway are those that encode functions involved in ERAD, such as EDEM, ERdj4, and PDI. Indeed, cells that are deficient in either IRE1 or XBP1 are defective in ERAD. Recently, the endoribonuclease activity of IRE1 was suggested to target and degrade ER-associated mRNAs as an additional mechanism to relieve the ER protein-folding load (Merksamer et al. 2008; Hollien et al. 2009).

The bZiP-containing activating transcription factor 6 (ATF6), the second arm of the UPR pathway, was identified as another regulatory protein that, like XBP1, binds the ER stress elements (ERSE-I and II), UPR elements (UPRE), and cAMP response elements (CRE) in the promoters of UPR-responsive genes (Yoshida et al. 1998). In this manner, increased expression of ERAD machinery, such as the ER degradation-enhancing $\alpha$-mannosidase-like protein (EDEM), increases the clearance and degradation of misfolded proteins in the ER lumen (Kokame et al. 2001). There are two known alleles of ATF6, ATF6 $\alpha$ and ATF6 $\beta$, both synthesized in all tissues as ER transmembrane proteins. ATF6 $\alpha$ deletion sensitizes cells and animals to persistent ER stress. In vivo, this failure to recover from ER stress results in fatty liver, uncovering a potential connection between ER stress and lipid metabolism ( Wu et al. 2007). It was also reported that ATF6 $\alpha$ interacts with CRTC2 to antagonize the ability of CREB to activate gluconeogenesis in the liver (Wang et al. 2009). The transcriptional coactivator PGC- $1 \alpha$, that regulates several exerciseassociated aspects of skeletal muscle function, mediates the UPR in myotubes and skeletal muscle through coactivation of ATF6 $\alpha$. Efficient recovery from acute exercise is compromised in Atf6 $\alpha-/$ - mice (Wu et al. 2011). Thus, both ATF6 and XBP1, a transcriptional target of ATF6 that requires splicing by the endoribonuclease activity of IRE1, are considered as the predominant regulators of the adaptive UPR transcriptional response to resolve protein misfolding.

Activation of the third arm of the UPR is mediated through PERK, an ER-associated transmembrane serine/threonine protein kinase. On 
ER Stress and Its Functional Link to Mitochondria: Role in Cell Survival and Death

accumulation of unfolded proteins in the ER lumen, PERK dimerization and trans-autophosphorylation leads to activation of the kinase function that phosphorylates the $\alpha$ subunit of eukaryotic translation initiation factor (eIF $2 \alpha)$ at Ser51. This phosphorylation attenuates mRNA translation initiation to reduce protein synthesis and the protein folding demand on the ER (Harding et al. 1999, 2000a,b, 2001; Morimoto et al. 2004). There are three additional eIF2 $\alpha$ kinases, PKR (double-stranded RNA-activated protein kinase), GCN2 (general control nonderepressible kinase 2), and HRI (heme-regulated inhibitor kinase) that also phosphorylate Ser51 on eIF2 $\alpha$. The precise role of the individual eIF $2 \alpha$ kinases is somewhat unclear because a single stress can activate more than a single eIF2 $\alpha$ kinase. For example, PKR is also activated by ER stress and PKR can protect cells from ER stress and initiate inflammatory response signaling (Nakamura et al. 2010). In addition to translational attenuation, activation of PERK branch of the UPR also decreases transcription of several dependent genes such as that of ribosomal RNA (DuRose et al. 2009). Although phosphorylation of eIF $2 \alpha$ inhibits general translation initiation, it is required for the selective translation of several mRNAs. Two transcription factors that require eIF $2 \alpha$ phosphorylation are the activating transcription factors 4 and 5 (ATF4, ATF5). Expression profiling studies identified several genes, including those encoding amino acid biosynthesis and transport functions, antioxidative stress responses, and apoptosis genes, such as growth arrest and DNA damage 34 (GADD34) and CAAT/Enhancer binding protein (C/ EBP) homologous protein (CHOP) (Harding et al. 2000; Ma et al. 2002) that require PERK, eIF2 $\alpha$ phosphorylation, and ATF4 (Scheuner et al. 2001; Ron 2002; Harding et al. 2003). Lack of eIF $2 \alpha$ phosphorylation in $\beta$ cells caused a severe diabetic phenotype because of heightened and unregulated proinsulin translation, defective folding, and trafficking of ER cargo proteins, reduced expression of ER stress response and $\beta$ cell-specific genes, increased oxidative damage, and apoptosis. However, glucose intolerance and $\beta$ cell death in these mice were attenuated by a diet containing antioxidants (Back et al. 2009). It seems that phosphorylation of eIF $2 \alpha$ coordinately attenuates mRNA translation, prevents oxidative stress, and optimizes ER protein folding to support insulin production. The finding that increased proinsulin synthesis is sufficient to cause oxidative damage in $\beta$ cells may reflect events in the $\beta$ cell failure associated with insulin resistance in type 2 diabetes that include decreased insulin production, loss of $\beta$ cell-specific gene expression, increased expression of UPR genes, oxidative stress, and apoptosis (Huang and Tindall 2007; Laybutt et al. 2007).

\section{ER STRESS-DEATH RESPONSE}

Apparently, execution of the UPR program does not always result in successful and efficient alleviation of the ER stress and therefore under conditions of severe or prolonged stress signals, the UPR can also culminate in induction of apoptosis (Rao et al 2004). Both mitochondrial-dependent and -independent cell death pathways likely mediate apoptosis in response to ER stress. The ER might actually serve as a site where apoptotic signals are generated and integrated to elicit the death response. Several mechanisms by which apoptotic signals are generated at the ER include: (1) pro-apoptotic Bcl-2 proteins Bak and Bax are switched on by the IRE1 $\alpha$ pathway leading to regulated $\mathrm{Ca}^{2+}$ release from the ER (Hetz et al. 2006); (2) cleavage and activation of procaspase-12; (3) IRE1-mediated activation of ASK1 (apoptosis signal-regulating kinase 1)/JNK (c-Jun amino terminal kinase); and finally, (4) PERK/ eIF2 $\alpha$-dependent induction of the proapoptotic transcription factor CEBP homologous protein (CHOP). CHOP is a downstream transcriptional target of ATF6 and PERK/eIF2/ ATF4. CHOP is a bZIP-containing transcription factor that inhibits the expression of Bcl2 , and activates transcription of several genes that encode apoptotic functions including GADD34, DR5, and TRB3 (McCullough et al. 2001). In addition, ER stress-induced IRE1 $\alpha$ phosphorylation leads to recruitment of TRAF2 
(tumor necrosis factor receptor-associated factor 2) and ASK1 to the cytosolic leaflet of ER membrane (Kawamori et al. 2003). Simultaneous activation of the PERK and IRE1 pathways also impacts NF-KB-IKk signaling pathway during ER stress by either activation of IKk or degradation of the p65 subunit ( $\mathrm{Hu}$ et al. 2006).

The mechanism of ER stress-induced apoptosis through Bak and Bax, that localize to both ER and mitochondria, has been shown to be associated with release of ER calcium with concomitant increase of mitochondrial calcium (Nutt et al. 2002). The $\mathrm{Ca}^{2+}$ released from the ER enters the mitochondria leading to depolarization of the inner membrane, cytochrome $c$ release, and activation of the Apaf-1 (apoptosis protease-activating factor 1)/procaspase-9-regulated apoptosis pathway. The mechanism by which ER stress is directly coupled to activation of caspases, particularly caspase 12, which was initially characterized by Nakagawa and Yuan (2000), remains somewhat elusive. The significance of ER stress-associated caspase 12 activation remains enigmatic because a functional caspase 12 is not conserved in humans.

Finally, analysis of gene-deleted mice has provided additional insight into ER stressinduced apoptosis. Cells from Apaf-1-deficient mice are susceptible to ER stress-induced apoptosis, indicating the existence of nonmitochondrial cell death pathways. Similarly, Bak/Bax double knockout, Caspase-12-/and $C h o p^{-1-}$ MEFs all show partial resistance to ER stress-induced apoptosis, further supporting the idea that they facilitate the apoptotic response on ER stress. Although, caspase-12-deficient and CHOP-deficient mice show no developmental defects, they display protection to genetically imposed or environmentally imposed ER stress. There are studies that indicate that ER stress-induced apoptosis may have a mitochondrial component (Deniaud et al. 2008). Overall, it seems PERK serves as a critical control point that determines commitment to cell death or promotes survival (Rutkowski et al. 2006; Ron and Walter 2007). However, there remain critical gaps in our understanding of the ability of individual UPR initiators to recognize and respond to various forms of ER stress and then engage distinct survival or death responses under different cellular environments.

\section{ER-MITOCHONDRIA INTERACTIONS}

The classical concept of mitochondria as the cell's powerhouse and as an isolated organelle has been profoundly challenged over the last two decades with the realization that mitochondria function within a highly dynamic integrated reticular network that is continually remodeled by both fusion and fission events. Both the ER and mitochondria are presently accepted as dynamic organelles capable of modifying their structure and function in response to changing environmental conditions. ER and mitochondria interact both physiologically and functionally, and one of the most critical aspects of this interaction is calcium signaling between the two organelles (Fig. 2). ER and mitochondria form close contacts with $20 \%$ of the mitochondrial surface in direct contact with the ER (Kornmann et al. 2009). These contacts through which the ER communicates with mitochondria are referred to as mitochondrialassociated membranes (MAM) (Vance 1990). These physical associations have pivotal roles in numerous cellular functions including $\mathrm{Ca}^{2+}$ signaling, lipid transport, energy metabolism, and cell survival. The ER-contiguous membranes also contain multiple phospholipids and glycosphingolipid synthesizing enzymes including long chain fatty acid-CoA ligase type 4 (FACl4) and phosphatidylserine synthase-1(PSS-1), and support direct transfer of lipids between the ER and mitochondria (Piccini et al. 1998; Stone and Vance 2000). The interaction between the two organelles is mediated by mitochondrial shaping proteins and key chaperones including calnexin, calreticulin, ERp44, ERp57, grp75, and the sigma-1 receptor. Over the years, a number of MAM-specific proteins have been identified including many ion channel and transporter proteins (IP3 receptors [IP3R], VDAC, $\mathrm{Ca}^{2+}$ ATPase, etc.), ubiquitin ligases, vesicular-sorting proteins, 
ER Stress and Its Functional Link to Mitochondria: Role in Cell Survival and Death

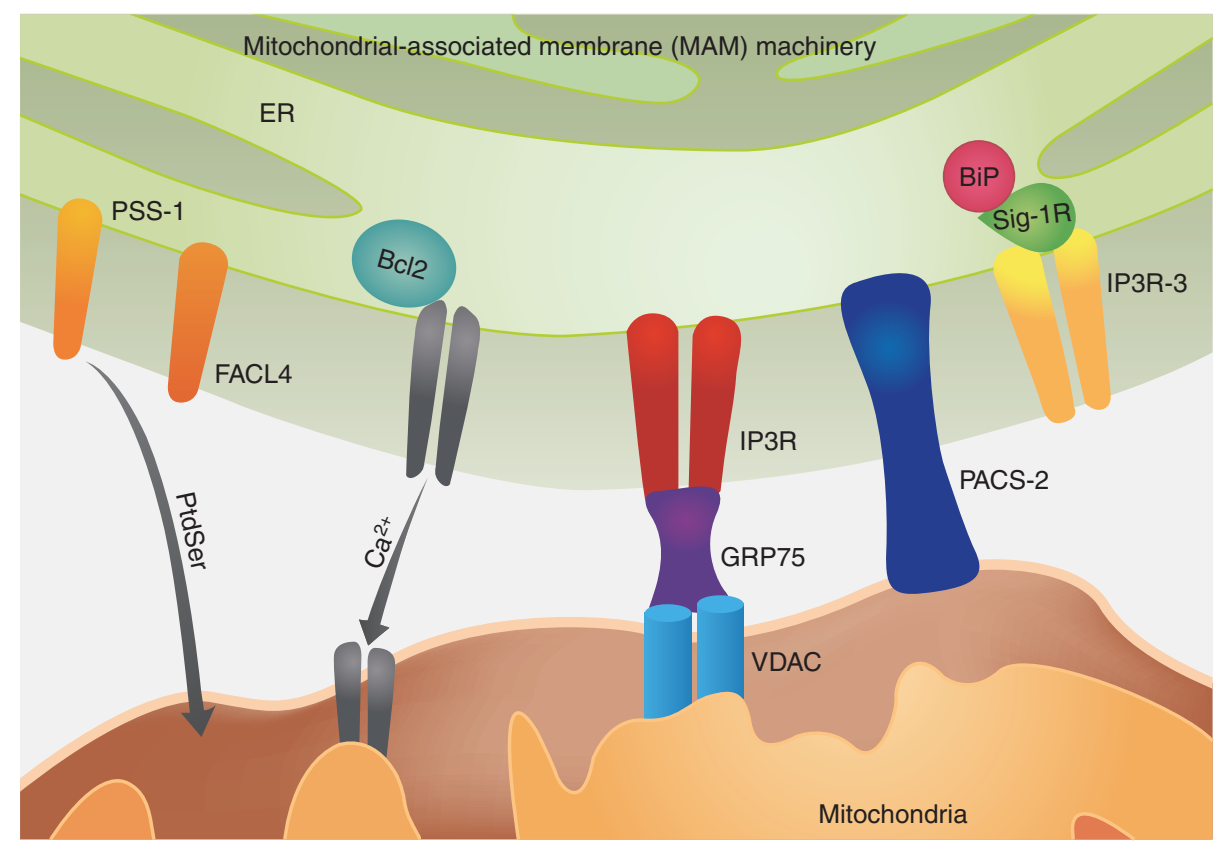

Figure 2. MAMs support the lipid transfer from ER to mitochodria through enzymes FACL4 and PSS-1. MAMs are enriched in chaperones like sigma-1Rs and they colacalize with BiP and IP3R. A multifunctional sorting protein that controls the ER-mitochondria axis Mitochondrial chaperone grp75 is a link between $\mathrm{ER} \mathrm{Ca}^{2+}$-release channel IP3R and isoform of VDAC.

electron transport chain proteins, and mitochondrial fusion proteins. Most of these proteins are ER proteins with only a few belonging to the mitochondria such as the VDAC and the uniporters. The mitochondrial-shaping proteins that are involved in modulating these two organelles are Dynamin-related protein-1 (DRP1) (Smirnova et al. 2001) and mitofusin 1 and 2 (Mfn-1 and dMfn2) that regulate mitochondrial fission and fusion, respectively (Chen et al. 2003). The molecular machinery mediating fusion and fission events are very intricate requiring the independent but coordinated processing of both the outer and inner mitochondrial membranes. These proteins, including DRP1, Mfn1, and Mfn2, were originally identified in yeast but many of these genes have orthologs in mammals and belong to a large GTPase protein family. The vesicularsorting protein, PACS-2 (phosphor-acidic cluster sorting protein 2) is a multifunctional sorting protein that controls the ER-mitochondria axis and the role of this axis in cellular homeostasis and apoptosis (Simmen et al. 2005). PACS-2 is required for the intimate association of mitochondria with ER. PACS-2 depletion results in mitochondrial fragmentation and uncouples this organelle from ER indicating that PACS-2 might be involved in ER protein folding and $\mathrm{Ca}^{2+}$ homeostasis (Szabadkai et al. 2004).

\section{$\mathrm{Ca}^{2+}$ SIGNALING AT THE MAM}

An increasing body of evidence unequivocally suggests that the function of the ER is intimately connected with that of the mitochondria with $\mathrm{Ca}^{2+}$ signaling being at the hub of this interorganelle interaction. Mitochondria play significant roles in shaping the $\mathrm{Ca}^{2+}$ signal released from the ER. Under normal physiological conditions, the bulk of the $\mathrm{Ca}^{2+}$ resides within the ER lumen and, during cellular events requiring a $\mathrm{Ca}^{2+}$ signal, a small bolus is released into 
the cytoplasm only to be resequestered later and with a small proportion crossing the outer mitochondrial membrane. The $\mathrm{ER} \mathrm{Ca}^{2+}$ functions both as a reservoir and simultaneously controls the activity of chaperones responsible for protein folding and processing (Rizzuto and Pozzan 2006). A great deal of recent evidence also shows that $\mathrm{Ca}^{2+}$ uptake into the mitochondria is controlled by specific proteins residing at the outer and inner mitochondrial membranes interface, namely the voltagedependent anion channel (VDAC) and the $\mathrm{Ca}^{2+}$ uniporter (Duchen and Szabadkai 2010) and with mitochondrial $\mathrm{Ca}^{2+}$ being expelled by antiporters in an exchange process for either $\mathrm{Na}^{+}$or $\mathrm{H}^{+}$. Thus, the antiporter and the exchanger maintain mitochondrial membrane potential and optimal $\mathrm{Ca}^{2+}$ concentrations in the mitochondria. At the same time, important cellular processes that connect apoptosis to ERmitochondria interactions is manifested when alterations in $\mathrm{Ca}^{2+}$ homeostatic mechanisms result in massive and/or a prolonged mitochondrial $\mathrm{Ca}^{2+}$ overload.

The most important molecular component of $\mathrm{Ca}^{2+}$ handling machinery of the ER is represented by the $\mathrm{IP}_{3} \mathrm{Rs}$ that are primarily clustered in the MAM regions where ER is closely juxtaposed to the mitochondria and thereby delineating these zones as primary subcellular microdomains of $\mathrm{Ca}^{2+}$ transfer from the ER to the mitochondria (Rizzuto et al. 1998). The release of $\mathrm{Ca}^{2+}$ from ER stores by IP3Rs has implications in numerous models of apoptosis as deletion of IP3R gene by genetic ablation or antisense strategy increases resistance to apoptosis (Blackshaw et al. 2000). There are three isoforms of the IP3R gene and recent data shows that the type 3 gene (IP3R-3) localized to the MAM plays a selective role in apoptosis induction by selectively transmitting apoptotic $\mathrm{Ca}^{2+}$ signals into mitochondria, whereas the type 1 gene (IP3R-1) preferentially mediates cytosolic $\mathrm{Ca}^{2+}$ mobilization (Mendes et al. 2005). Finally, a fascinating aspect of this interaction is the finding that in response to survival signals, Akt interacts and phosphorylates IP3Rs, significantly reducing their $\mathrm{Ca}^{2+}$ release activity (Szado et al. 2008).

\section{MOLECULAR CHAPERONES AT THE MAM}

Both $\mathrm{Ca}^{2+}$-binding and glucose-regulated chaperones are abundantly found on the membranes as well as lumens of both ER and mitochondria. These chaperones serve as constitutive $\mathrm{ER} \mathrm{Ca}^{2+}$ pools and also facilitate proper protein folding in a $\mathrm{Ca}^{2+}$-dependent manner. Some of these chaperones also couple to and regulate the activities of specific $\mathrm{Ca}^{2+}$ channels. A novel chaperone that specifically targets the MAM is the sigma- $1 \mathrm{R}$ receptor, a ligand-operated $\mathrm{Ca}^{2+}$-sensitive ER chaperone that colocalizes with $\mathrm{IP}_{3} \mathrm{R}$ at the MAM. Sigma $1 \mathrm{Rs}$ form a $\mathrm{Ca}^{2+}$-sensitive machinery or complex at the MAM along with GRP78/BiP, and are now believed to prolong calcium signaling from the ER to mitochondria by stabilizing IP3R at the MAMs (Hayashi and Su 2007). The IP3 receptors are vulnerable to ubiquitylation and proteasomal degradation on stimulation by $\mathrm{IP}_{3}$, and thus stabilization of the $\mathrm{IP}_{3}$ receptors during intracellular signaling by the Sigma $1 \mathrm{R}$ is critical to maintain proper $\mathrm{Ca}^{2+}$ signaling both in the cytosol and in the mitochondria. Another important chaperone found at the MAM is the Grp75, and a recent study showed that cytosolic Grp75 tethers the ligandbinding domain of the IP3 receptors to VDAC1. The mitochondrial chaperone Grp75 regulates IP3R-mediated mitochondrial $\mathrm{Ca}^{2+}$ signaling (Szabadkai et al. 2006). Isoform 1 of VDAC is physically linked to the $\mathrm{ER} \mathrm{Ca}^{2+}$ release channel IP3R through Grp75, highlighting chaperonemediated conformational coupling between the IP3R and the mitochondrial $\mathrm{Ca}^{2+}$ uptake machinery. ER chaperones calnexin and calreticulin are also compartmentalized at MAM (Hayashi and Su 2007; Myhill et al. 2008). In addition to providing buffering capacity in ER, calreticulin inhibits the IP3 receptormediated $\mathrm{Ca}^{2+}$ signaling by using its highaffinity, low-capacity, $\mathrm{Ca}^{2+}$-binding domain (Camacho and Lechleiter 1995). Calnexin can regulate the $\mathrm{Ca}^{2+}$ ATPase activity via proteinprotein interaction (Roderick et al. 2000). Another ER chaperone ERp57 can work in conjunction with calreticulin and facilitate in regulating the activity of $\mathrm{Ca}^{2+}$-ATPase ( $\mathrm{Li}$ and 
ER Stress and Its Functional Link to Mitochondria: Role in Cell Survival and Death

Camacho 2004). ERp44 chaperone can inhibit type I IP3 receptors in a planar lipid bilayer system thereby modulating the IP3 receptor signaling (Anelli et al. 2003).

\section{$\mathrm{ER} \mathrm{Ca}^{2+}$ AND MITOCHONDRIAL PERMEABILITY TRANSITION}

From the previous sections, it is clear that the function of the ER is intimately connected with that of the mitochondria, and a key process that links these ER-mitochondria interactions is the control of $\mathrm{Ca}^{2+}$ signaling. The mitochondria have a unique structure that contains two membranes that separates four distinct compartments, the outer mitochondrial membrane (OMM), the inner mitochondrial membrane (IMM), the space between these two membranes, and finally the matrix. The recent discovery that a massive and/or a prolonged influx of calcium into mitochondria can lead to the formation and opening of a large highconductivity pore in the IMM, known as the mitochondrial permeability transition pore (PTP), a channel or "uniporter" driven by a large electrochemical gradient is critical for maintaining IMM stability. Mitochondrial $\mathrm{Ca}^{2+}$ overload and cellular redox status are considered the most potent inducers of permeability transition. The molecular identity of the PTP is not very clear but it seems to be comprised of the voltage-dependent anion channel (VDAC) localized in the OMM, the adenine nucleotide translocase (ANT) in the IMM, and cyclophilin $\mathrm{D}$ (a peptidyl-prolyl isomerase) localized in the matrix. Under normal physiological conditions, the opening and closing of PTP controls the homeostasis of mitochondria and regulates the matrix volume, $\mathrm{Ca}^{2+}$ flux, and the redox equilibrium and matrix $\mathrm{pH}$. Under various pathophysiological conditions, permeabilization of the OMM can result in the release into the cytosol of a series of pro-apoptotic proteins such as cytochrome c, apoptosis-inducing factor (AIF), and smac/Diablo resulting in the demise of the cell through the execution of the apoptotic program involving proteases and nucleases. Recent studies have shown that the mitochondrial PTP plays a significant role in ischemia reperfusion injury in the heart as well as after myocardial infarction leading to breakdown of mitochondria and necrotic cell death (Halestrap 2010). The permeabilization of the OMM is also determined primarily by an interaction between the pro-Bax and Bak and antiapoptotic Bcl-2 family members (Welch et al. 2009). Intriguingly, the MAM has emerged as a key point in the regulation of mitochondrial $\mathrm{Ca}^{2+}$ and the redox equilibrium, functioning as a central hub of cellular signaling. The two abundant MAM-associated ion channels, the IP3R and the VDAC resident on the OMM, primarily mediate $\mathrm{Ca}^{2+}$ transfer between the two organelles and ultimately determining $\mathrm{Ca}^{2+}$ load (Fig. 3). Both these channels also function as redox sensors, and several proteins including regulators of autophagy (Beclin-1) and apoptosis (Bcl-2 and $\mathrm{Bad}$ ) cluster around this core platform of $\mathrm{Ca}^{2+}$ channels. Antiapoptotic Bcl-2 members (Bcl-2 and $\mathrm{Bcl} 2-\mathrm{XL}$ ) have been suggested to exert their effect by suppressing $\mathrm{Ca}^{2+}$ transfer from the ER to mitochondria. Overexpression of Bcl-2 decreases ER luminal $\mathrm{Ca}^{2+}$, thereby inhibiting $\mathrm{Ca}^{2+}$ - and oxidative stress-mediated cell death (Pinton et al. 2000). On the other hand, studies have shown that knockdown of the proapoptotic members Bax and Bak increases the interaction of Bcl-2 with type-1 IP3Rs and promotes both the phosphorylation of the IP3R and constitutive $\mathrm{Ca}^{2+}$ leak through the IP3Rs (Oakes et al. 2005). Thus, Bcl-2 family members regulate IP3R-1 phosphorylation to control the rate of $\mathrm{ER} \mathrm{Ca}^{2+}$ release and in a way regulate cell fate by determining the probability of opening the mitochondrial PTP.

\section{FUTURE DIRECTIONS}

There has been tremendous progress over the past two decades in comprehending the mechanisms underlying ER stress-dependent UPR activation. The cellular processes linking protein folding, oxidative stress, and ER stress are tightly linked, and how aberrations in this signaling network communicate to the mitochondria to regulate cell death or survival is a 
J.D. Malhotra and R.J. Kaufman

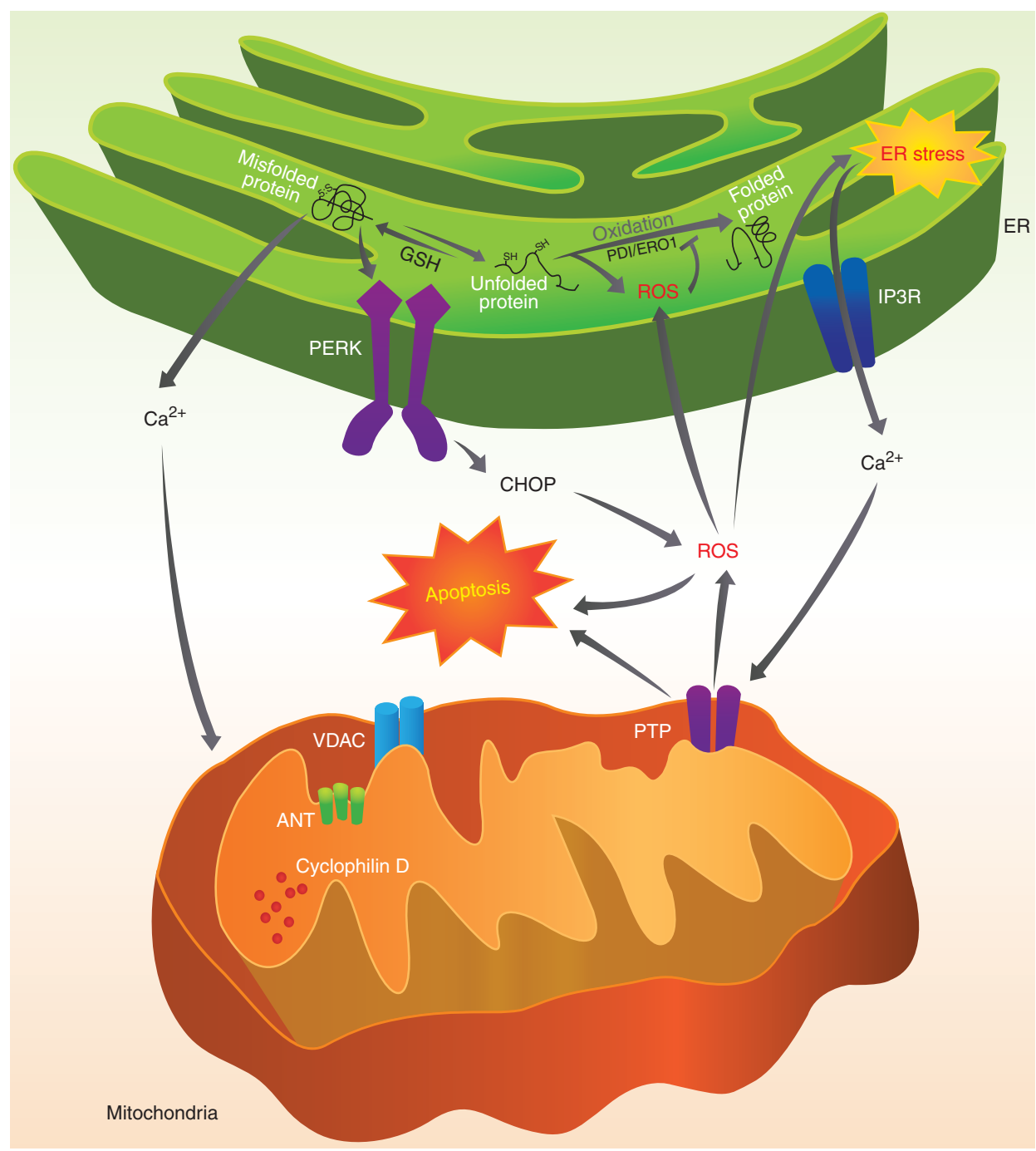

Figure 3. ER-mitochondria cross talk is mediated by protein misfolding within the ER, which results in release of calcium from the intracellular stores into the cytosol through IP3Rs. $\mathrm{Ca}^{2+}$ has a critical role in this ER and mitochondrial cross talk. $\mathrm{Ca}^{2+}$ released from ER is taken up by mitochondria and results in calcium overload and induces depolarization of permeability transition pore (PTP) and induces apoptotic stimuli to release caspases.

fascinating emerging area of investigation. Future studies are required to understand how these stresses affect protein folding, misfolding, and secretion in vivo. These studies should identify under what physiological and pathological states these pathways are activated in vivo and how they finally influence disease outcome. A coherent understanding of the ERmitochondria cross talk and nexus will certainly aid in the development of specific therapeutic strategies to treat diseases associated with protein misfolding and inflammation such as obesity, diabetes, and neurodegeneration, as well as those associated with aging.

\section{ACKNOWLEDGMENTS}

The authors appreciate the work of Janet L. Mitchell in preparing this article and Jennifer Harley in assisting with the illustrations. 
ER Stress and Its Functional Link to Mitochondria: Role in Cell Survival and Death

Portions of this work were supported by NIH grants DK042394, HL052173, and HL057346 (R.J.K.). Additionally, J.D.M. is supported by AHA grant 10SDG2610338.

\section{REFERENCES}

Anelli T, Alessio M, Bachi A, Bergamelli L, Bertoli G, Camerini S, Mezghrani A, Ruffato E, Simmen T, Sitia R. 2003. Thiol-mediated protein retention in the endoplasmic reticulum: The role of ERp44. EMBO J 22: 5015-5022.

Aragón T, van Anken E, Pincus D, Serafimova IM, Korennykh AV, Rubio CA, Walter P. 2009. Messenger RNA targeting to endoplasmic reticulum stress signalling sites. Nature 457: 736-740.

Back SH, Scheuner D, Han J, Song B, Ribick M, Wang J, Gildersleeve RD, Pennathur S, Kaufman RJ. 2009. Translation attenuation through eIF $2 \alpha$ phosphorylation prevents oxidative stress and maintains the differentiated state in $\beta$ cells. Cell Metab 10: 13-26.

Bertolotti A, Zhang Y, Hendershot LM, Harding HP, Ron D. 2000. Dynamic interaction of BiP and ER stress transducers in the unfolded-protein response. Nat Cell Biol 2: $326-332$.

Blackshaw S, Sawa A, Sharp AH, Ross CA, Snyder SH, Khan AA. 2000. Type 3 inositol 1,4,5-trisphosphate receptor modulates cell death. FASEB J 14: 1375-1379.

Calfon M, Zeng H, Urano F, Till JH, Hubbard SR, Harding HP, Clark SG, Ron D. 2002. IRE1 couples endoplasmic reticulum load to secretory capacity by processing the XBP-1 mRNA. Nature 415: 92-96.

Camacho P, Lechleiter JD. 1995. Calreticulin inhibits repetitive intracellular $\mathrm{Ca}^{2+}$ waves. Cell 82: 765-771.

Chen X, Shen J, Prywes R. 2002. The luminal domain of ATF6 senses endoplasmic reticulum (ER) stress and causes translocation of ATF6 from the ER to the Golgi. J Biol Chem 277: 13045-13052.

Chen H, Detmer SA, Ewald AJ, Griffin EE, Fraser SE, Chan DC. 2003. Mitofusins Mfn1 and Mfn2 coordinately regulate mitochondrial fusion and are essential for embryonic development. J Cell Biol 160: 189-200.

Cox JS, Shamu CE, Walter P. 1993. Transcriptional induction of genes encoding endoplasmic reticulum resident proteins requires a transmembrane protein kinase. Cell 73: 1197-1206.

Credle JJ, Finer-Moore JS, Papa FR, Stroud RM, Walter P. 2005. On the mechanism of sensing unfolded protein in the endoplasmic reticulum. Proc Natl Acad Sci 102: 18773-18784.

Deniaud A, Sharaf el dein O, Maillier E, Poncet D, Kroemer G, Lemaire C, Brenner C. 2008. Endoplasmic reticulum stress induces calcium-dependent permeability transition, mitochondrial outer membrane permeabilization and apoptosis. Oncogene 27: 285-299.

Dorner AJ, Wasley LC, Kaufman RJ. 1990. Protein dissociation from GRP78 and secretion are blocked by depletion of cellular ATP levels. Proc Natl Acad Sci 87: 7429-7432.

Duchen MR, Szabadkai G. 2010. Roles of mitochondria in human disease. Essays Biochem 47: 115-137.
DuRose JB, Scheuner D, Kaufman RJ, Rothblum LI, Niwa M. 2009. Phosphorylation of eukaryotic translation initiation factor $2 \alpha$ coordinates rRNA transcription and translation inhibition during endoplasmic reticulum stress. Mol Cell Biol 29: 4295-4307.

Halestrap AP. 2010. A pore way to die: The role of mitochondria in reperfusion injury and cardioprotection. Biochem Soc Trans 38: 841-860.

Harding HP, Zhang Y, Ron D. 1999. Protein translation and folding are coupled by an endoplasmic-reticulum-resident kinase. Nature 397: 271-274.

Harding HP, Novoa I, Zhang Y, Zeng H, Wek R, Schapira M, Ron D. 2000a. Regulated translation initiation controls stress-induced gene expression in mammalian cells. Mol Cell 6: 1099-1108.

Harding HP, Zhang Y, Bertolotti A, Zeng H, Ron D. 2000b. Perk is essential for translational regulation and cell survival during the unfolded protein response. Mol Cell 5: 897-904.

Harding HP, Novoa I, Bertolotti A, Zeng H, Zhang Y, Urano F, Jousse C, Ron D. 2001. Translational regulation in the cellular response to biosynthetic load on the endoplasmic reticulum. Cold Spring Harb Symp Quant Biol 66: 499-508.

Harding HP, Zhang Y, Zeng H, Novoa I, Lu PD, Calfon M, Sadri N, Yun C, Popko B, Paules R, et al. 2003. An integrated stress response regulates amino acid metabolism and resistance to oxidative stress. Mol Cell 11: 619-633.

Hayashi T, Su TP. 2007. Sigma-1 receptor chaperones at the ER-mitochondrion interface regulate $\mathrm{Ca}^{2+}$ signaling and cell survival. Cell 131: 596-610.

Hetz C, Bernasconi P, Fisher J, Lee AH, Bassik MC, Antonsson B, Brandt GS, Iwakoshi NN, Schinzel A, Glimcher LH, et al. 2006. Proapoptotic BAX and BAK modulate the unfolded protein response by a direct interaction with IRE1 $\alpha$. Science 312: 572-576.

Hollien J, Lin JH, Li H, Stevens N, Walter P, Weissman JS. 2009. Regulated Ire1-dependent decay of messenger RNAs in mammalian cells. J Cell Biol 186: 323-331.

Hu P, Han Z, Couvillon AD, Kaufman RJ, Exton JH. 2006. Autocrine tumor necrosis factor $\alpha$ links endoplasmic reticulum stress to the membrane death receptor pathway through IRE1 $\alpha$-mediated NF-kappaB activation and down-regulation of TRAF2 expression. Mol Cell Biol 26: 3071-3084.

Huang H, Tindall DJ. 2007. Dynamic FoxO transcription factors. J Cell Sci 120: 2479-2487.

Kaufman RJ. 2002. Orchestrating the unfolded protein response in health and disease. J Clin Invest 110: 13891398.

Kawamori D, Kajimoto Y, Kaneto H, Umayahara Y, Fujitani Y, Miyatsuka T, Watada H, Leibiger IB, Yamasaki Y, Hori M. 2003. Oxidative stress induces nucleo-cytoplasmic translocation of pancreatic transcription factor PDX-1 through activation of c-Jun NH(2)-terminal kinase. Diabetes 52: 2896-2904.

Kincaid MM, Cooper AA. 2007. Misfolded proteins traffic from the endoplasmic reticulum (ER) due to ER export signals. Mol Biol Cell 18: 455-463. 
J.D. Malhotra and R.J. Kaufman

Kleizen B, Braakman I. 2004. Protein folding and quality control in the endoplasmic reticulum. Curr Opin Cell Biol 16: 343-349.

Kokame K, Kato H, Miyata T. 2001. Identification of ERSE-II, a new cis-acting element responsible for the ATF6-dependent mammalian unfolded protein response. J Biol Chem 276: 9199-9205.

Korennykh AV, Egea PF, Korostelev AA, Finer-Moore J, Zhang C, Shokat KM, Stroud RM, Walter P. 2009. The unfolded protein response signals through high-order assembly of Ire1. Nature 457: 687-693.

Kornmann B, Currie E, Collins SR, Schuldiner M, Nunnari J, Weissman JS, Walter P. 2009. An ER-mitochondria tethering complex revealed by a synthetic biology screen. Science 325: 477-481.

Laybutt DR, Hawkins YC, Lock J, Lebet J, Sharma A, Bonner-Weir S, Weir GC. 2007. Influence of diabetes on the loss of $\beta$ cell differentiation after islet transplantation in rats. Diabetologia 50: 2117-2125.

Lee K, Tirasophon W, Shen X, Michalak M, Prywes R, Okada T, Yoshida H, Mori K, Kaufman RJ. 2002. IRE1mediated unconventional mRNA splicing and S2Pmediated ATF6 cleavage merge to regulate XBP1 in signaling the unfolded protein response. Genes Dev 16: 452-466.

Lee AH, Iwakoshi NN, Glimcher LH. 2003. XBP-1 regulates a subset of endoplasmic reticulum resident chaperone genes in the unfolded protein response. Mol Cell Biol 23: 744-759.

Li Y, Camacho P. 2004. $\mathrm{Ca}^{2+}$-dependent redox modulation of SERCA 2b by ERp57. J Cell Biol 164: 35-46.

Li H, Korennykh AV, Behrman SL, Walter P. 2010. Mammalian endoplasmic reticulum stress sensor IRE1 signals by dynamic clustering. Proc Natl Acad Sci 107: 1611316118.

Liu CY, Xu Z, Kaufman RJ. 2003. Structure and intermolecular interactions of the luminal dimerization domain of human IRE1 $\alpha$. J Biol Chem 278: 17680-17687.

Ma Y, Hendershot LM. 2004. ER chaperone functions during normal and stress conditions. $J$ Chem Neuroanat 28: $51-65$.

Ma Y, Brewer JW, Diehl JA, Hendershot LM. 2002. Two distinct stress signaling pathways converge upon the $\mathrm{CHOP}$ promoter during the mammalian unfolded protein response. J Mol Biol 318: 1351-1365.

McCullough KD, Martindale JL, Klotz LO, Aw TY, Holbrook NJ. 2001. Gadd153 sensitizes cells to endoplasmic reticulum stress by down-regulating Bcl2 and perturbing the cellular redox state. Mol Cell Biol 21: 1249-1259.

Mendes CC, Gomes DA, Thompson M, Souto NC, Goes TS, Goes AM, Rodrigues MA, Gomez MV, Nathanson MH, Leite MF. 2005. The type III inositol 1,4,5-trisphosphate receptor preferentially transmits apoptotic $\mathrm{Ca}^{2+}$ signals into mitochondria. J Biol Chem 280: 40892-40900.

Merksamer PI, Trusina A, Papa FR. 2008. Real-time redox measurements during endoplasmic reticulum stress reveal interlinked protein folding functions. Cell 135: 933-947.

Molinari M. 2007. N-glycan structure dictates extension of protein folding or onset of disposal. Nat Chem Biol 3: $313-320$.
Mori K, Ma W, Gething MJ, Sambrook J. 1993. A transmembrane protein with a cdc ${ }^{2+} / \mathrm{CDC} 28$-related kinase activity is required for signaling from the ER to the nucleus. Cell 74: 743-756.

Morimoto H, Okamura H, Yoshida K, Kitamura S, Haneji T. 2004. Okadaic acid induces apoptosis through doublestranded RNA-dependent protein kinase/eukaryotic initiation factor- $2 \alpha$ pathway in human osteoblastic MG63 cells. J Biochem 136: 433-438.

Myhill N, Lynes EM, Nanji JA, Blagoveshchenskaya AD, Fei H, Carmine Simmen K, Cooper TJ, Thomas G, Simmen T. 2008. The subcellular distribution of calnexin is mediated by PACS-2. Mol Biol Cell 19: 2777-2788.

Nadanaka S, Okada T, Yoshida H, Mori K. 2007. Role of disulfide bridges formed in the luminal domain of ATF6 in sensing endoplasmic reticulum stress. Mol Cell Biol 27: 1027-1043.

Nakagawa T, Zhu H, Morishima N, Li E, Xu J, Yankner BA, Yuan J. 2000. Caspase-12 mediates endoplasmic-reticulum-specific apoptosis and cytotoxity by amyloid-beta. Nature 6: 98-103.

Nakamura T, Furuhashi M, Li P, Cao H, Tuncman G, Sonenberg N, Gorgun CZ, Hotamisligil GS. 2010. Doublestranded RNA-dependent protein kinase links pathogen sensing with stress and metabolic homeostasis. Cell 140: $338-348$.

Nutt LK, Pataer A, Pahler J, Fang B, Roth J, McConkey DJ, Swisher SG. 2002. Bax and Bak promote apoptosis by modulating endoplasmic reticular and mitochondrial $\mathrm{Ca}^{2+}$ stores. J Biol Chem 277: 9219-9225.

Oakes SA, Scorrano L, Opferman JT, Bassik MC, Nishino M, Pozzan T, Korsmeyer SJ. 2005. Proapoptotic BAX and BAK regulate the type 1 inositol trisphosphate receptor and calcium leak from the endoplasmic reticulum. Proc Natl Acad Sci 102: 105-110.

Oikawa D, Kimata Y, Kohno K. 2007. Self-association and $\mathrm{BiP}$ dissociation are not sufficient for activation of the ER stress sensor Ire1. J Cell Sci 120: 1681-1688.

Patil C, Walter P. 2001. Intracellular signaling from the endoplasmic reticulum to the nucleus: The unfolded protein response in yeast and mammals. Curr Opin Cell Biol 13: 349-355.

Piccini M, Vitelli F, Bruttini M, Pober BR, Jonsson JJ, Villanova M, Zollo M, Borsani G, Ballabio A, Renieri A. 1998. FACL4, a new gene encoding long-chain acyl-CoA synthetase 4, is deleted in a family with Alport syndrome, elliptocytosis, and mental retardation. Genomics 47: 350-358.

Pinton P, Ferrari D, Magalhães P, Schulze-Osthoff K, Di Virgilio F, Pozzan T, Rizzuto R. 2000. Reduced loading of intracellular $\mathrm{Ca}^{2+}$ stores and downregulation of capacitative $\mathrm{Ca}^{2+}$ influx in Bcl-2-overexpressing cells. J Cell Biol 148: $857-862$.

Rao RV, Ellerby HM, Bredesen DE. 2004. Coupling endoplasmic reticulum stress to the cell death program. Cell Death Differ 11: 372-380.

Rizzuto R, Pozzan T. 2006. Microdomains of intracellular $\mathrm{Ca}^{2+}$ : Molecular determinants and functional consequences. Physiol Rev 86: 369-408.

Rizzuto R, Pinton P, Carrington W, Fay FS, Fogarty KE, Lifshitz LM, Tuft RA, Pozzan T. 1998. Close contacts 
ER Stress and Its Functional Link to Mitochondria: Role in Cell Survival and Death

with the endoplasmic reticulum as determinants of mitochondrial $\mathrm{Ca}^{2+}$ responses. Science 280: 1763-1766.

Roderick HL, Lechleiter JD, Camacho P. 2000. Cytosolic phosphorylation of calnexin controls intracellular $\mathrm{Ca}^{2+}$ oscillations via an interaction with SERCA2b. J Cell Biol 149: $1235-1248$.

Ron D. 2002. Proteotoxicity in the endoplasmic reticulum: Lessons from the Akita diabetic mouse. J Clin Invest 109: $443-445$.

Ron D, Walter P. 2007. Signal integration in the endoplasmic reticulum unfolded protein response. Nat Rev Mol Cell Biol 8: 519-529.

Rutkowski DT, Arnold SM, Miller CN, Wu J, Li J, Gunnison KM, Mori K, Sadighi Akha AA, Raden D, Kaufman RJ. 2006. Adaptation to ER stress is mediated by differential stabilities of prosurvival and proapoptotic mRNAs and proteins. PLoS Biol 4: e374.

Scheuner D, Song B, McEwen E, Liu C, Laybutt R, Gillespie P, Saunders T, Bonner-Weir S, Kaufman RJ. 2001. Translational control is required for the unfolded protein response and in vivo glucose homeostasis. Mol Cell 7: 1165-1176.

Schroder M, Kaufman RJ. 2005. The mammalian unfolded protein response. Annu Rev Biochem 74: 739-789.

Shen X, Ellis RE, Lee K, Liu CY, Yang K, Solomon A, Yoshida H, Morimoto R, Kurnit DM, Mori K, et al. 2001. Complementary signaling pathways regulate the unfolded protein response and are required for $C$. elegans development. Cell 107: 893-903.

Simmen T, Aslan JE, Blagoveshchenskaya AD, Thomas L, Wan L, Xiang Y, Feliciangeli SF, Hung CH, Crump CM, Thomas G. 2005. PACS-2 controls endoplasmic reticulum-mitochondria communication and Bid-mediated apoptosis. EMBO J 24: 717-729.

Smirnova E, Griparic L, Shurland DL, van der Bliek AM. 2001. Dynamin-related protein Drp1 is required for mitochondrial division in mammalian cells. Mol Biol Cell 12: 2245-2256.

Stone SJ, Vance JE. 2000. Phosphatidylserine synthase-1 and -2 are localized to mitochondria-associated membranes. J Biol Chem 275: 34534-34540.

Szabadkai G, Simoni AM, Chami M, Wieckowski MR, Youle RJ, Rizzuto R. 2004. Drp-1-dependent division of the mitochondrial network blocks intraorganellar $\mathrm{Ca}^{2+}$ waves and protects against $\mathrm{Ca}^{2+}$-mediated apoptosis. Mol Cell 16: 59-68.

Szabadkai G, Simoni AM, Bianchi K, De Stefani D, Leo S, Wieckowski MR, Rizzuto R. 2006. Mitochondrial dynamics and $\mathrm{Ca}^{2+}$ signaling. Biochim Biophys Acta 1763: 442-449.

Szado T, Vanderheyden V, Parys JB, De Smedt H, Rietdorf K, Kotelevets L, Chastre E, Khan F, Landegren U, Söderberg
O, et al. 2008. Phosphorylation of inositol 1,4,5-trisphosphate receptors by protein kinase B/Akt inhibits $\mathrm{Ca}^{2+}$ release and apoptosis. Proc Natl Acad Sci 105: 24272432.

Vance JE. 1990. Phospholipid synthesis in a membrane fraction associated with mitochondria. J Biol Chem 265: $7248-7256$.

Wang Y, Vera L, Fischer WH, Montminy M. 2009. The CREB coactivator CRTC2 links hepatic ER stress and fasting gluconeogenesis. Nature 460: 534-537.

Welch C, Santra MK, El-Assaad W, Zhu X, Huber WE, Keys RA, Teodoro JG, Green MR. 2009. Identification of a protein, G0S2, that lacks Bcl-2 homology domains and interacts with and antagonizes Bcl-2. Cancer Res 69: 6782-6789.

Wu J, Kaufman RJ. 2006. From acute ER stress to physiological roles of the unfolded protein response. Cell Death Differ 13: 374-384.

Wu J, Rutkowski DT, Dubois M, Swathirajan J, Saunders T, Wang J, Song B, Yau GD, Kaufman RJ. 2007. ATF6 $\alpha$ optimizes long-term endoplasmic reticulum function to protect cells from chronic stress. Dev Cell 13: 351-364.

Wu J, Ruas JL, Estall JL, Rasbach KA, Choi JH, Ye L, Boström P, Tyra HM, Crawford RW, Campbell KP, et al. 2011. The unfolded protein response mediates adaptation to exercise in skeletal muscle through a PGC-1 $\alpha /$ ATF6 $\alpha$ complex. Cell Metab 13: 160-169.

Yamamoto K, Sato T, Matsui T, Sato M, Okada T, Yoshida H, Harada A, Mori K. 2007. Transcriptional induction of mammalian ER quality control proteins is mediated by single or combined action of ATF $6 \alpha$ and XBP1. Dev Cell 13: 365-376.

Yoshida H, Haze K, Yanagi H, Yura T, Mori K. 1998. Identification of the cis-acting endoplasmic reticulum stress response element responsible for transcriptional induction of mammalian glucose-regulated proteins. Involvement of basic leucine zipper transcription factors. J Biol Chem 273: 33741-33749.

Yoshida H, Matsui T, Yamamoto A, Okada T, Mori K. 2001. XBP1 mRNA is induced by ATF6 and spliced by IRE1 in response to ER stress to produce a highly active transcription factor. Cell 107: 881-891.

Yoshida H, Matsui T, Hosokawa N, Kaufman RJ, Nagata K, Mori K. 2003. A time-dependent phase shift in the mammalian unfolded protein response. Dev Cell 4: 265-271.

Zhou J, Liu CY, Back SH, Clark RL, Peisach D, Xu Z, Kaufman RJ. 2006. The crystal structure of human IRE1 luminal domain reveals a conserved dimerization interface required for activation of the unfolded protein response. Proc Natl Acad Sci 103: 14343-14348. 


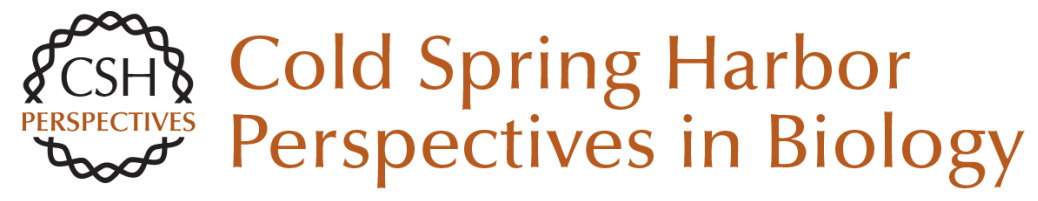

\section{ER Stress and Its Functional Link to Mitochondria: Role in Cell Survival and Death}

Jyoti D. Malhotra and Randal J. Kaufman

Cold Spring Harb Perspect Biol 2011; doi: 10.1101/cshperspect.a004424 originally published online August 2, 2011

\section{Subject Collection Protein Homeostasis}

Proteome-Scale Mapping of Perturbed

Proteostasis in Living Cells

Isabel Lam, Erinc Hallacli and Vikram Khurana

Pharmacologic Approaches for Adapting

Proteostasis in the Secretory Pathway to

Ameliorate Protein Conformational Diseases Jeffery W. Kelly

Cell-Nonautonomous Regulation of Proteostasis

in Aging and Disease

Richard I. Morimoto

The Autophagy Lysosomal Pathway and

Neurodegeneration Steven Finkbeiner

Functional Modules of the Proteostasis Network Gopal G. Jayaraj, Mark S. Hipp and F. Ulrich Hartl

Protein Solubility Predictions Using the CamSol

Method in the Study of Protein Homeostasis Pietro Sormanni and Michele Vendruscolo

Recognition and Degradation of Mislocalized

Proteins in Health and Disease

Ramanujan S. Hegde and Eszter Zavodszky

The Nuclear and DNA-Associated Molecular Chaperone Network

Zlata Gvozdenov, Janhavi Kolhe and Brian C. Freeman
The Amyloid Phenomenon and Its Significance in

Biology and Medicine

Christopher M. Dobson, Tuomas P.J. Knowles and Michele Vendruscolo

A Chemical Biology Approach to the Chaperome

in Cancer--HSP90 and Beyond

Tony Taldone, Tai Wang, Anna Rodina, et al.

Proteostasis in Viral Infection: Unfolding the

Complex Virus-Chaperone Interplay

Ranen Aviner and Judith Frydman

The Proteasome and Its Network: Engineering for

Adaptability

Daniel Finley and Miguel A. Prado

Functional Amyloids

Daniel Otzen and Roland Riek

Chaperone Interactions at the Ribosome Elke Deuerling, Martin Gamerdinger and Stefan G. Kreft

Mechanisms of Small Heat Shock Proteins Maria K. Janowska, Hannah E.R. Baughman, Christopher N. Woods, et al.

Structure, Function, and Regulation of the Hsp90 Machinery

Maximilian M. Biebl and Johannes Buchner

For additional articles in this collection, see http://cshperspectives.cshlp.org/cgi/collection/

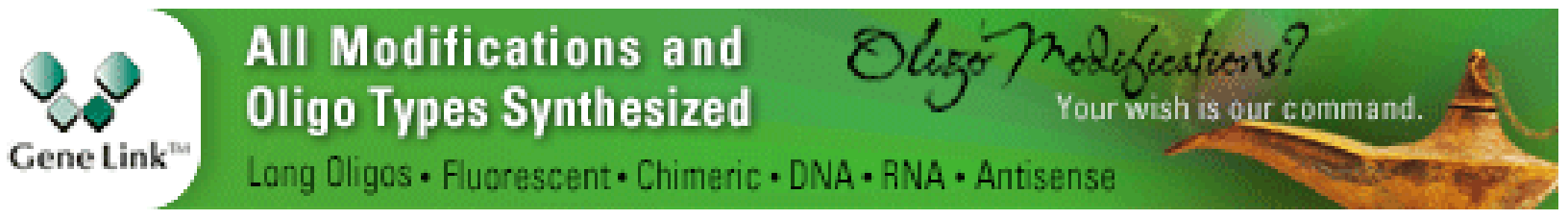


For additional articles in this collection, see http://cshperspectives.cshlp.org/cgi/collection/

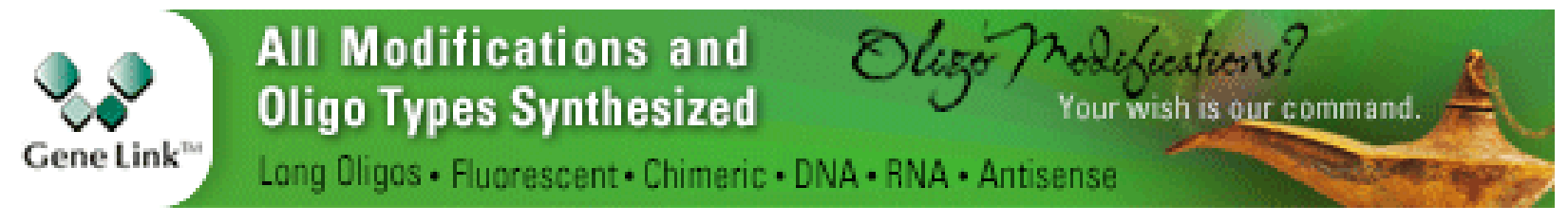

Copyright @ 2011 Cold Spring Harbor Laboratory Press; all rights reserved 